\title{
Severe neuropsychiatric symptoms due to vitamin b12 deficiency: a case of pernicious anemia or metformin use?
}

\author{
Joana Urbano ${ }^{1,2} ;$ Ana Catarina Fernandes 3 ; Pestana Ferreira ${ }^{1,2}$; Joana Pimenta ${ }^{1,2}$ \\ ${ }^{1}$ Internal Medicine Department, Centro Hospitalar São João, Porto, Portugal. ${ }^{2}$ University of Porto Medical School, Porto, Portugal \\ ${ }^{3}$ Medical Oncology Department, Centro Hospitalar São João, Porto, Portugal
}

\begin{abstract}
Pernicious anemia is the leading cause of vitamin B12 deficiency and requires an early diagnose and proper treatment since it is a reversible form of acute psychosis and demyelinating nervous system disease ${ }^{1}$. Less frequently, metformin therapy, especially on high doses and for long time treatment, can also cause vitamin B12 deficit, but the coexistence of anemia and neuropsychiatric symptoms is rarely seen.

We describe a case of a 49-year-old adult patient with type 2 diabetes medicated with $850 \mathrm{mg}$ of metformin per day, which presented a clinical scenario of severe vitamin B12 deficiency with associated pancytopenia, postero-lateral demyelinization of spinal cord and acute psychosis. The investigation was initially negative for pernicious anemia, as upper endoscopy and autoantibodies against intrinsic factor and parietal cells were negative. After excluding other causes, and because serious vitamin B12 deficiency associated with metformin is less frequent in patients with short treatment duration and low daily doses, suspicion of pernicious anemia was maintained. Six months after being discharged, he repeated upper endoscopy with biopsy, which revealed atrophic gastritis and blood autoantibodies became positive. He recovered completely from the neuropsychiatric and hematological dysfunctions with parenteric vitamin B12 treatment. There are several uncommon aspects about this report, namely the severity of the clinical presentation, with serious multiorganic failure. Besides, it is also uncommon that a significant neuropsychiatric impairment coexist with profound bone marrow suppression ${ }^{2}$. Also of note is the importance of a great level of suspicion concerning pernicious anemia, since autoantibodies and upper endoscopy can be negative, especially on early phases ${ }^{1}$.
\end{abstract}

KEYWORDS: Megaloblastic anemia. Metformin. Neuropathy. Pernicious anemia. Psychosis. Vitamin B12.

\section{Introdution}

Pernicious anemia is a common cause of cyanocobalamine deficiency, which is characterized by an atrophy of all layers of gastric body and fundus, causing intrinsic factor deficit and subsequently impaired absorption of cyanocobalamine. Diagnosis is generally made by upper endoscopy. Autoantibodies against intrinsic factor and parietal cells have a sensibility of $50 \%$ and $80 \%$, respectively ${ }^{1}$.

Metformin can also decrease blood cyanocobalamine concentration by 14 to $30 \%$ and it happens in about 6 to $30 \%$ of patients treated with the drug, according to the literature ${ }^{3}$. The mechanism consists of inhibition of cyanocobalamineintrinsic factor complex absorption, a calcium-dependent step, so that it can be treated with calcium supplementation ${ }^{4}$. However, metformin rarely causes megaloblastic anemia, unless administered in high doses and for long time of treatment ${ }^{3}$.

When symptomatic, cyanocobalamine deficiency usually results in hematological and neurological signs and symptoms.
It causes megaloblastic anemia and, less commonly, hemolysis with pancytopenia. Neurological attainment usually consists of a sub-acute combined degeneration of the spinal cord with demyelination of the dorsal column, causing both motor and sensory deficits. Neuropsychiatric manifestations can also present with emotional lability, mania, paranoia, delusions, amnesia and psychosis ${ }^{1}$.

\section{Clinical case}

A 49-year-old man, without any psychiatric history, was admitted to the emergency department of our institution with a severe acute psychosis, agitated, with persecutory delirium, auditory hallucinations and both auto and hetero aggressiveness. He completed 4 years of the primary school. He was a carpenter, but had been unemployed for the last 4 years. His past medical history included type 2 diabetes mellitus diagnosed 3 years before and medicated with $850 \mathrm{mg}$ of metformin per day since that. He had good glycemic control and no target organ damage. He had also arterial hypertension stage 1 , with good blood pressure control with olmesartan $20 \mathrm{mg}$ plus hydroclorothyazide $12.5 \mathrm{mg}$ per day; active smoking habits; and no history of regular alcohol consumption. Almost one year before, his blood tests documented a mild macrocytic anemia (hemoglobin $(\mathrm{Hb}) 12.5 \mathrm{~g} / \mathrm{dL}$; mean corpuscular volume (MCV) 113.1fL) without any symptom. His wife noticed that in the last 4 months he became asthenic, prostrated and was losing weight. He seemed sad and anedonic. His state worsened on the last week before emergency department admission, becoming more worried and anxious, crying without reason, having almost total insomnia and anorexia. One day she caught him spying a group of masons at the garage, agitated, aggressive, speaking to himself a lot of delirious ideas, scared of being chased by them, and saying they were planning to kill him. She called the emergency line and he was brought to our emergency department. Laboratory blood samples revealed a pancytopenia, with much worse macrocytic anemia (Hb 10.1 g/dL, MCV 110.4fL), white blood count of $3.96 \times 10 \% / \mathrm{L}$, and platelet count of $161 \times 10^{\%} / \mathrm{L}$ (normal values: $180-500 \times 10^{9} / \mathrm{L}$ ). Toxicology screening (alcohol and drugs) was negative. Cerebral computed tomography revealed no lesions, namely vascular or other occupying space lesions. He was then admitted to psychiatric ward with the diagnosis of major depression with psychotic symptoms.

The first few days after his admission, constitutional symptoms worsened and hemoglobin dropped even further. Doctors documented neurologic deterioration and inability for walking and standing. Physical exam revealed a severe ataxic gate with positive Romberg sign, bilateral lower limb weakness, and hiperestesic sensations, as well as weak rotulian and absent aquilian reflexes. Patient complained about paresthesia of distal 2/3 of his legs and foots and he developed urinary incontinence. He was disoriented, with slowed speech, memory disturbance and impaired mathema- 
tic calculation. He pointed 18 on minimental state examination, corresponding to cognitive impairment (table 1 on the left). Electroencephalogram and cerebral and spinal magnetic resonance revealed no alterations and syphilis serology was negative. Laboratory reevaluation at this time showed an even worse macrocytic anemia (with a nadir of $\mathrm{Hb}$ of $8.5 \mathrm{~g} / \mathrm{dL}$, MCV $112.3 \mathrm{fL})$, neutropenia (1.66 $\left.\times 10^{\%} / \mathrm{L}\right)$ and thrombocytopenia (149×10\%/L). Lactic dehydrogenase was slightly increased to 242U/L (normal values: 135225U/L). Folic acid blood levels were normal but cyanocobalamin was undetectable. He was finally diagnosed with severe cyanocobalamine deficiency with associated pancytopenia (predominantly megaloblastic anemia), posterolateral demyelinization of spinal cord and acute psychosis. He started treatment with intramuscular cyanocobalamine $1 \mathrm{mg}$ per day and folic acid $5 \mathrm{mg}$ per day. Inadequate cyanocobalamine ingestion as well as causes of impaired gastric absorption such as previous surgeries or certain medications were excluded as causes of the deficiency. An upper endoscopy revealed no alterations suggesting atrophic gastritis and blood auto-antibodies against intrinsic factor and parietal cells were negative. Human immunodeficiency virus infection, celiac disease and drugs causing impaired intestinal absorption of cyanocobalamine were excluded. At that point we thought that metformin could be the cause of diminished B12 vitamin absorption.

As psychosis resolved and patient gained insight for his delirium, he was discharged to be followed on ambulatory clinics, maintaining parenteric treatment with cyanocobalamin on a monthly basis. On following months constitutional symptoms have improved as well as muscular weakness and gate instability. Cognitive impairment has almost resolved, and 5 months later the patient scored 29 points on minimental state examination (table 1 on the right). Paresthesia of inferior limbs resolved only after 8 months of treatment. Six months after being discharged, he repeated upper endoscopy with biopsy, which revealed atrophic gastritis and blood antibodies against intrinsic factor and parietal cells became positive.

\section{Discussion}

We have described a case of an adult with severe vitamin B12 deficiency due to pernicious anemia, with associated pancytopenia, postero-lateral demyelinization of spinal cord and acute psychosis. However, the cause of the deficit wasn't evident from the beginning. The fact that he was medicated with metformin, a drug known to interfere with vitamin B12 absorption, was a confounder factor during the etiology investigation.

Metformin is the drug of choice in the treatment of type 2 diabetes. The earliest studies on metformin and B12 deficiency were published in 1972. The prevalence of B12 deficiency in secondary care type 2 diabetes patients using metformin was estimated between 6 to 30\% but prevalence of anemia and neuropathy are generally not reported. Therefore, standard screening and/or supplementation of vitamin B12 in metformin treated type 2 diabetes pa-
Table 1. Minimental state examination at patient admission and after 5 months of treatment

\begin{tabular}{|c|c|c|}
\hline $\begin{array}{c}\text { Minimental State } \\
\text { Examinationl }\end{array}$ & $\begin{array}{l}\text { Evaluation } \\
\text { at admission }\end{array}$ & $\begin{array}{l}\text { Evaluation after } 5 \\
\text { months of treatment }\end{array}$ \\
\hline $\begin{array}{l}\text { 1. ORIENTATION } \\
\text { What year is it? } \\
\text { What month is it? } \\
\text { What day of the month is it? } \\
\text { What day of the week is it? } \\
\text { What season is it? } \\
\text { In which country are we? } \\
\text { In which district are we? } \\
\text { In which town are we? } \\
\text { In which building are we? } \\
\text { In which floor are we? }\end{array}$ & $\begin{array}{l}0 \\
1 \\
0 \\
1 \\
0 \\
1 \\
1 \\
1 \\
1 \\
0\end{array}$ & $\begin{array}{l}1 \\
1 \\
1 \\
1 \\
1 \\
1 \\
1 \\
1 \\
1 \\
1\end{array}$ \\
\hline $\begin{array}{l}\text { 2. REGISTRATION } \\
\text { Pear } \\
\text { Cat } \\
\text { Ball }\end{array}$ & $\begin{array}{l}1 \\
1 \\
1\end{array}$ & $\begin{array}{l}1 \\
1 \\
1\end{array}$ \\
\hline $\begin{array}{l}\text { 3. ATTENTION AND } \\
\text { CALCULATION } \\
\text { Subtract } 100-7 \\
\text { Minus } 7 \\
\text { Minus } 7 \\
\text { Minus } 7 \\
\text { Minus } 7\end{array}$ & $\begin{array}{l}0 \\
0 \\
0 \\
0 \\
0\end{array}$ & $\begin{array}{l}1 \\
1 \\
1 \\
1 \\
1\end{array}$ \\
\hline $\begin{array}{l}\text { 4. RECALL } \\
\text { Pear } \\
\text { Cat } \\
\text { Ball }\end{array}$ & $\begin{array}{l}1 \\
0 \\
0\end{array}$ & $\begin{array}{l}1 \\
1 \\
0\end{array}$ \\
\hline $\begin{array}{l}\text { 5. NAMING } \\
\text { Watch } \\
\text { Pencil }\end{array}$ & $\begin{array}{l}1 \\
1\end{array}$ & $\begin{array}{l}1 \\
1\end{array}$ \\
\hline $\begin{array}{l}\text { 6. REPEATING } \\
\text { "No ifs, ands or buts." }\end{array}$ & 1 & 1 \\
\hline $\begin{array}{l}\text { 7. FOLLOW A 3-STAGE } \\
\text { COMMAND } \\
\text { Take a paper in your hand } \\
\text { Fold it in half } \\
\text { And put it on the floor. }\end{array}$ & $\begin{array}{l}1 \\
1 \\
1\end{array}$ & $\begin{array}{l}1 \\
1 \\
1\end{array}$ \\
\hline $\begin{array}{l}\text { 8. READ AND OBEY } \\
\text { "Close your eyes." }\end{array}$ & 1 & 1 \\
\hline 9. WRITE A SENTENCE & 1 & 1 \\
\hline 10. COPY THE DESIGN SHOWN & 18 & 29 \\
\hline
\end{tabular}


tients is not established ${ }^{5}$. Besides, it takes over a year of negative vitamin B12 balance caused by subnormal vitamin B12 absorption to result in the elimination of nerve and blood vitamin B12 stores. A state of severe B12 deficiency, as a consequence of prolonged metformin administration, may result in peripheral nerve damage, a potentially reversible etiology. This may be confused with peripheral neuropathy of diabetes, a clinical scenario that could lead to permanent nerve loss ${ }^{6}$.

However, other authors defend that, although current guidelines make no recommendations on the detection and prevention of vitamin B12 deficiency during treatment with metformin, routine assessment of vitamin B12 levels during long term treatment should be done ${ }^{4}$. Sanchéz et al. propose that daily use of 3 or more tablets of $850 \mathrm{mg}$ of metformin is significantly associated with low plasmatic vitamin B12 levels, independently of sex, age, alcohol consumption or use of $\mathrm{H} 2$ antagonist/proton pump inhibitors ${ }^{7}$.

Another important aspect is that not all of low plasma B12 vitamin levels mean "deficiency" as well as not all of high plasma B12 levels mean "sufficiency." In suspected cases, a combined assay of holotranscobalamin (active B12) and the metabolic marker, methylmalonic acid, can identify the deficit. When B12 vitamin is internalized and is able to maintain the B12-dependent intercellular enzyme activities (methionine synthase and methylmalonyl-CoA mutase), plasma total homocysteine and methylmalonic acid will be within the reference range. Patients taking metformin have lower serum B12 and holotranscobalamin but comparable metabolic markers, namely homocysteine and methylmalonic acid ${ }^{8}$. In our particular patient, it seemed unlikely that such markedly reduced cyanocobalamine levels could be due only to the use of such a low metformin dose of $850 \mathrm{mg} /$ day. In fact, vitamin B12 deficiency occurs more frequently in patients with longer duration of metformin use and in those taking larger daily doses ${ }^{9}$. Therefore, it was important that other etiologies were actively investigated and excluded, namely malnutrition and causes of impaired absorption.

This report describes a case of severe depletion of vitamin B12 on a 49-year-old adult, which is not the characteristic age group of cyanocobalamine deficiency. In fact, elderly patients are a special population at risk for this deficit due to several conditions as high prevalence of gastrointestinal diseases and polymedication, namely with antacids and antiepileptics that can interfere with vitamin B12 absorption. ${ }^{10}$. Children can also exhibit cyanocobalamine deficiency due to insufficient nutritional support, as is the case of offspring of strict vegetarian mothers with B12 deficit during pregnancy. The deficiency becomes rapidly symptomatic within months because children storage is too limited. Consequences are mainly hematological and neurological, with progressive encephalopathy ${ }^{11}$.

At last, we had to search for another common cause of cyanocobalamine deficiency, pernicious anemia. It consists of an autoimmune gastritis that results from the destruction of gastric parietal cells, leading to the absence of intrinsic factor to bind ingested B12 vitamin. It is not known yet whether or not Helicobacter pylori plays a causative role in this process. Despite being more frequent among patients between 70 and 80 years ${ }^{1}$, it can affect all age groups. Noteworthy, the degree of bone marrow suppression is typically inversely related to both the presence and severity of neurological involvement ${ }^{2}$. We describe an unusual case of a patient with severe vitamin B12 deficiency together with profound hematological dysfunctions and florid neuropsychiatric impairment. The severity of multiorganic attainment, the difficulty in finding the cause of the deficit and the excellent response to treatment make this clinical case rare and remarkable.

\section{Conclusion}

The coexistence of significant anemia and neurological deficits caused by severe vitamin B12 deficiency is thought to be rare ${ }^{2}$. In fact, the severity of the clinical presentation, with serious multiorganic failure that responded well to treatment makes this case a rare report of vitamin B12 deficiency. We also highlight the importance of an early diagnosis and treatment because full recovery of neurological deficits is dependent on their extend and duration ${ }^{1}$. This report also stresses the importance of a great level of suspicion concerning pernicious anemia as the cause of vitamin B12 deficiency, since autoantibodies and upper endoscopy can be negative, particularly on early phases ${ }^{1}$. At least, it is also of note the fact that metformin use could have contributed to the final vitamin B12 deficit.

\section{Bibliography}

1. Stabler S. Vitamin B12 Deficiency. N Engl J Med 2013;368:149-60.

2. Rannelli L, Watterson R, Rupang P, Leung A. Vitamin B12 deficiency with combined hematological and neuropsychiatric derangements: a case report. J Med Case Rep 2014;8:277.

3. Mazokopakis E, Starakis I. Recommendations for diagnosis and management of metformin-induced vitamin B12 (Cbl) deficiency. Diabetes Res Clin Pract 2012;97:35967.

4. Jager J, Kooy A, Lehert P, Wulffelé MG, van der Kolk J, Bets D, et al. Long term treatment with metformin in patients with type 2 diabetes and risk of vitamin B-12 deficiency: randomised placebo controlled trial. BMJ 2010;340:C2181.

5. Groot-Kamphuis D, van Dijk P, Groenier K, Houweling S, Bilo H, Kleefstra N. Vitamin $\mathrm{B} 12$ deficiency and the lack of its consequences in type 2 diabetes patients using metformin. Neth J Med 2013;71:386-90.

6. Bauman W, Shaw S, Jayatilleke E, Spungen A, Herbert V. Increased Intake of Calcium Reverses Vitamin B12 Malabsorption Induced by Metformin. Diabetes Care 2000;23:1227-31

7. Sánchez H, Masferrer D, Lera L, Arancibia E, Ángel B, Albala C. Déficit de vitamina B12 asociado con altas dosis de metformina en adultos mayores diabéticos. Nutr Hosp 2014;29:1394-400

8. Obeid R. Metformin Causing Vitamin B12 Deficiency: A Guilty Verdict Without Sufficient Evidence. Diabetes Care 2014;37:e22-e3.

9. Sun-Hye K, Ki-Ho S, Kyung-Do H, Yong-Moon P, Seung-Hyun K, Hye-Soo K, et al. Association of Vitamin B12 Deficiency and Metformin Use in Patients with Type 2 Diabetes. J Korean Med Sci 2014;29:965-72.

10. Torio I, Bagney A, Caballero M, Jiménez-Arriero M, Rodríguez-Jiménez R. Psicosis por déficit de vitamina B12 en un paciente de edad avanzada. Rev Neurol 2014;59:45-7

11. Gutiérrez-Aguilar G, Abenia-Usón P, García-Cazorla A, Vilaseca M, Campistol J. Encefalopatía con aciduria metilmalónica y homocistinuria secundaria a un déficit de aporte exógeno de vitamina B12. Rev Neurol 2005;40:605-8. 